\title{
Long-Term Follow-Up of a Phase I/II Study of ProSavin, a Lentiviral Vector Gene Therapy for Parkinson's Disease
}

\author{
Stéphane Palfi, ${ }^{1,2}{ }^{*}$ Jean Marc Gurruchaga, ${ }^{1,2}$ Hélène Lepetit, ${ }^{1,2}$ Katy Howard, ${ }^{3}$ \\ G. Scott Ralph, Sarah Mason, Gaëtane Gouello,,2 Philippe Domenech,, ${ }^{1,2}$ Philip C. Buttery, \\ Philippe Hantraye, Nicola J. Tuckwell, ${ }^{3}$ Roger A. Barker, and Kyriacos A. Mitrophanous ${ }^{3}$ \\ ${ }^{1}$ AP-HP, Groupe Hospitalier Henri-Mondor, DHU PePsy, Neurochirurgie, Psychiatrie Créteil, France; ${ }^{2}$ Université Paris 12, Faculté de Médecine, IMRB INSERM U 955 \\ Team 14 Créteil, France; ${ }^{3}$ Oxford BioMedica Ltd., Oxford, United Kingdom; ${ }^{4}$ John van Geest Centre for Brain Repair, Department of Clinical Neuroscience, \\ Addenbrooke's Hospital, Cambridge, United Kingdom; and ${ }^{5}$ CEA, DSV FBM, MIRCen and CNRS URA2210, Fontenay-aux-Roses, France.
}

Parkinson's disease is typically treated with oral dopamine replacement therapies. However, long-term use is complicated by motor fluctuations from intermittent stimulation of dopamine receptors and off-target effects. ProSavin, a lentiviral vector based gene therapy that delivers local and continuous dopamine, was previously shown to be well tolerated in a Phase I/II first-in-human study, with significant improvements in motor behavior from baseline at 1 year. Here, patients with Parkinson's disease from the open-label trial were followed up in the long term to assess the safety and efficacy of ProSavin after bilateral injection into the putamen. Fifteen patients who were previously treated with ProSavin have been followed for up to 5 years, with some having been seen for 8 years. Eight patients received deep brain stimulation at different time points, and their subsequent assessments continued to assess safety. Ninety-six drug-related adverse events were reported ( 87 mild, 6 moderate, 3 severe) of which more than half occurred in the first year. The most common drug-related events were dyskinesias (33 events, 11 patients) and on-off phenomena (22 events, 11 patients). A significant improvement in the defined "off" Unified Parkinson's Disease Rating Scale part III motor scores, compared to baseline, was seen at 2 years (mean score $29 \cdot 2$ vs. $38 \cdot 4, n=14, p<0.05$ ) and at 4 years in 8/15 patients. ProSavin continued to be safe and well tolerated in patients with Parkinson's disease. Moderate improvements in motor behavior over baseline continued to be reported in the majority of patients who could still be evaluated up to 5 years of follow-up.

Keywords: gene therapy, lentiviral vector, Parkinson's disease, dopamine

\section{INTRODUCTION}

THE CORE MOTOR FEATURES of Parkinson's disease are associated with a loss of dopaminergic neurons in the substantia nigra pars compacta and their projection to the posterior striatum where dopamine is released. ${ }^{1,2}$ Current Parkinson's disease treatments focus on the acute restoration of dopaminergic activity in the striatum through daily oral administration of the dopamine precursor L-Dopa, and/or dopaminergic agonists. ${ }^{3}$ Although such treatments provide good control of many of the motor features in the initial stages of the disease, L-Dopa therapy becomes less reliable with disease progression as a range of motor and nonmotor complications emerge, such as on-off phenomena, peak-dose dyskinesias, and a range of neuropsychiatric and cognitive problems. ${ }^{4,5}$ A therapeutic approach that restores long-term continuous dopaminergic function, restricted to the dopamine-depleted striatum, may provide an effective and durable treatment while minimizing off-target effects. ${ }^{6}$

Gene therapy approaches for Parkinson's disease using adeno-associated virus vectors have been shown to be well tolerated in early-phase clinical trials of mid- to late-stage patients. ${ }^{7-12}$

${ }^{*}$ Correspondence: Prof. Stéphane Palfi, AP-HP, Groupe Henri-Mondor Albert-Chenevier, Neurochirurgie, Créteil, F-94010, France. E-mail: stephane.palfi@aphp.fr

Stéphane Palfi et al. 2018; Published by Mary Ann Liebert, Inc. This Open Access article is distributed under the terms of the Creative Commons Attribution Noncommercial License (http://creativecommons.org/licenses/by-nc/4.0/) which permits any noncommercial use, distribution, and reproduction in any medium, provided the original author(s) and the source are credited. 
The therapeutic rationale for these studies was based on: (i) neuroprotection of nigral dopaminergic neurons and their projections through delivery of genes encoding a neurotrophic factor, ${ }^{10,13}$ (ii) enhanced conversion of L-Dopa to dopamine by gene transfer of the enzyme aromatic amino acid decarboxylase (AADC), ${ }^{7-9}$ or (iii) modulation of basal ganglia outputs by delivery of glutamic acid decarboxylase (GAD) to the subthalamic nucleus. ${ }^{11,12}$ Although Phase I studies reported encouraging efficacy data, follow-up studies showed no or modest difference in motor improvements compared to placebo-control patients. ${ }^{12,13}$

The 1 year results were previously reported of the open-label part of a Phase I/II clinical trial evaluating the safety and efficacy of ProSavin-an equine infectious anemia virus (EIAV)-based gene therapy approach aimed at local and continuous dopamine replacement to the motor striatum of Parkinson's disease patients. ${ }^{14}$ The ProSavin vector encodes the three dopamine biosynthetic enzymes-tyrosine hydroxylase (TH), AADC, and GTP-cyclohydrolase 1 (CH1) —and has been shown to convert transduced non-dopaminergic striatal neurons into dopamine-producing cells. ${ }^{15}$

This clinical study showed that ProSavin was well tolerated, with promising indications of efficacy. ${ }^{14}$ Here, the long-term follow-up of these patients is reported, including assessments of safety and efficacy in 13 patients up to at least 5 years, and in some cases to 8 years, post treatment with ProSavin.

\section{METHODS}

\section{Study design}

A detailed description of the Phase I/II study has been previously published. ${ }^{14}$ All patients were subsequently enrolled into this open-label followup study to investigate the long-term safety and efficacy of ProSavin for up to 10 years post treatment. The study protocols were approved by the ethics committee of each participating institution and complied with the Declaration of Helsinki, current Good Clinical Practice guidelines, and local laws and regulations. The Phase I/II study and ongoing open-label follow-up are registered with the ClinicalTrials.gov registry (NTC00627588 and NCT01856439; EudraCT numbers: 2007-00110926 and 2009-017253-35).

\section{Participants}

As previously described, 15 patients with idiopathic Parkinson's disease, as defined by the diagnostic criteria from the core assessment program for surgical interventional therapies (CAPSIT [1999]), received ProSavin in one of four dose cohorts. ${ }^{14}$ Entry criteria included: age between 48 and 65 years, disease duration of at least 5 years, Hoehn and Yahr stage 3 or 4 in the off state, Unified Parkinson's Disease Rating Scale (UPDRS) part III (off) scores between 20 and 60, motor complications associated with L-Dopa therapy, a stable medication regimen for at least 4 weeks prior to surgery, and $\geq 50 \%$ improvement in the UPDRS part III score between the off and on states in response to an acute L-Dopa challenge (Table 1).

\section{Procedure}

All patients received ProSavin via bilateral injections into the striatum under general anesthesia. Three dose levels of ProSavin were assessed in four patient cohorts. Three patients were included at dose level 1 (low dose, $2 \times 10^{7}$ transducing units [TU]; cohort 1), six patients at dose level 2 (mid dose, $4 \times 10^{7} \mathrm{TU}$; cohorts $2 \mathrm{a}$ and $2 \mathrm{~b}$ ), and six patients at dose level 3 (high dose, $1 \times 10^{8}$ TU; cohort 3 ). A modified delivery method of administration was introduced for cohorts $2 \mathrm{~b}$ and 3 to increase the rate of delivery and enhance the distribution of the vector. The modified delivery method included a change from 1 to $3 \mu \mathrm{L} / \mathrm{min}$, with a reduction of diameter of the cannula from 25 to 28 gauge and from five needle tracks (each with five depots each) to three needle tracks (each with one depot; see Supplementary Data; Supplementary Data are available online at www.liebertpub.com/humc).

Table 1. Baseline demographic data

\begin{tabular}{lcccccc}
\hline Patients & Cohort & $\begin{array}{c}\text { Age } \\
\text { (years) }\end{array}$ & $\begin{array}{c}\text { Disease } \\
\text { duration } \\
\text { (years) }\end{array}$ & $\begin{array}{c}\text { UPDRS } \\
\text { motor score, } \\
\text { off/on }\end{array}$ & $\begin{array}{c}\text { Total } \\
\text { UPDRS } \\
\text { score, off/on }\end{array}$ & $\begin{array}{c}\text { L-Dopa } \\
\text { equivalent } \\
\text { dose }\end{array}$ \\
\hline L1 & 1 & 62 & 8 & $23 / 6$ & $49 / 19$ & 2,547 \\
L2 & 1 & 57 & 8 & $30 / 8$ & $61 / 24$ & 1,329 \\
L3 & 1 & 58 & 16 & $28 / 11$ & $70 / 35$ & 1,998 \\
M4 & 2a & 57 & 17 & $29 / 8$ & $63 / 20$ & 2,164 \\
M5 & 2a & 56 & 12 & $30 / 14$ & $58 / 24$ & 1,572 \\
M6 & $2 a$ & 49 & 9 & $34 / 7$ & $74 / 23$ & 2,523 \\
M7 & $2 b$ & 64 & 9 & $49 / 19$ & $83 / 31$ & 1,785 \\
M8 & $2 b$ & 59 & 13 & $38 / 15$ & $67 / 31$ & 1,088 \\
M9 & $2 b$ & 57 & 15 & $46 / 9$ & $68 / 20$ & 1,775 \\
H10 & 3 & 48 & 22 & $37 / 8$ & $59 / 21$ & 1,535 \\
H11 & 3 & 58 & 10 & $35 / 10$ & $71 / 27$ & 1,844 \\
H12 & 3 & 61 & 26 & $52 / 13$ & $91 / 25$ & 1,180 \\
H13 & 3 & 63 & 16 & $49 / 23$ & $90 / 52$ & 1,691 \\
H14 & 3 & 57 & 19 & $52 / 23$ & $94 / 47$ & 699 \\
H15 & 3 & 55 & 9 & $44 / 18$ & $71 / 30$ & 1,593 \\
Mean & NA & 57.4 & 13.9 & $38 / 13$ & $71 / 29$ & 1,688 \\
SD & NA & 4.47 & 5.47 & $9.61 / 5.70$ & $13.17 / 9.74$ & 505.03 \\
\hline
\end{tabular}

Patients are listed in the order in which they received treatment. UPDRS, Unified Parkinson's Disease Rating Scale; L, low $\left(1.9 \times 10^{7} \mathrm{TU}\right)$; $\mathrm{M}$, mid $\left(4.0 \times 10^{7} \mathrm{TU}\right) ; \mathrm{H}$, high dose $\left(1 \times 10^{8} \mathrm{TU}\right) ; 0 \mathrm{Off}$, off-medication state; $0 \mathrm{n}$, on-medication state. 


\section{Outcomes}

The primary endpoints of the Phase I/II study were the number and severity of adverse events (AEs) associated with ProSavin administration and motor responses as assessed using the UPDRS part III in the defined off state 6 months post vector administration. The UPDRS is a widely used assessment tool used in patients with Parkinson's disease. It is made up of six different sections. Part I evaluates mentation, behavior, and mood. Part II evaluates activities of daily life (ADLs), including speech, swallowing, handwriting, dressing, hygiene, falling, levels of salivation, turning in bed, walking, and cutting food. Part III is a clinicianscored itemized motor evaluation. Part IV evaluates the complications of dopaminergic therapy. Part V gives a Hoehn and Yahr staging of the severity of the Parkinson's disease. Part VI contains the Schwab and England ADL scale. Patients were thereafter evaluated at least every 6 months for 3 years and thereafter on an annual basis (which will be up to 10 years in the open-label follow-up). AEs were assessed at every visit, and all events were recorded, including those that were reported spontaneously or on general questioning and those observed directly by the investigators. Efficacy assessments, including the UPDRS parts I, II, and III (in the off and on states) and UPDRS part IV, were done at least every 6 months up to 3 years and yearly thereafter up to year 6 , with a final assessment planned at year 10. Eight patients have received deep brain stimulation (DBS) at different time points post ProSavin injections, and subsequent assessments for these patients were not included in the UPDRS analysis. UPDRS off assessments were performed in the practically defined off state following overnight drug withdrawal. UPDRS on assessments were performed $1 \mathrm{~h}$ after a dose of L-Dopa that was tailored for each patient at baseline, with the same dose being used at each subsequent assessment. Individual doses of dopaminergic medication were kept constant throughout follow-up, unless alterations were required in response to AEs. Doses were assessed at every visit and expressed as L-Dopa equivalent daily dose (LEDD). Quality of life (using the Parkinson's Disease Questionnaire [PDQ-39]) was assessed at least every 6 months up to 3 years and yearly thereafter.

\section{Statistical analysis}

The UPDRS and PDQ-39 scores were analyzed by a Wilcoxon paired test at 24 months. Data management and statistical summaries were performed by Quanticate (UK) Ltd. (Hitchin, United Kingdom). Verbatim AEs were coded us- ing the Medical Dictionary for Regulatory Activities (MedDRA).

\section{RESULTS \\ Patients}

All baseline patient characteristics have been previously described. With the exception of one patient (H14) who declined assessment of efficacy after the 12-month assessment (but continued safety assessments), all patients were assessed for efficacy for at least 2 years of follow-up (Fig. 1).

Eight patients in total received bilateral DBS of the subthalamic nucleus after the 2- (M7, M8, H11), 3- (H14), 4- (H12), 5- (M4, H10), or 6-year (M6) assessment battery. Post-DBS assessments were not included in this analysis except for overall safety.

\section{Safety}

Across all time points of follow-up, treatmentemergent AEs were reported in every patient, with the majority (575/671) considered to be unrelated to ProSavin (Supplementary Table S1, S2, S3). Thirty serious AEs were reported across 12 patients, and all were considered unrelated or unlikely to be related to the study drug and the surgical procedure. Two deaths were reported: L1 after their year 6 assessment (peritonitis), and M7 after year 4 (cardio-respiratory arrest), with neither death considered related to ProSavin treatment or to their underlying Parkinson's disease.

There were 96 drug-related AEs reported post treatment (Table 2), and the majority of these ( $n=87 ; 91 \%)$ were mild and/or occurred in the first year of follow-up $(n=57 ; 61 \%)$. The most common ProSavin-related AEs, in both the first year post treatment and follow-up thereafter, were increased dyskinesias (33 AEs in 11 patients; 30 mild, 2 moderate, 1 severe) and on-off phenomena (22 AEs in 11 patients; all mild). Increased dyskinesias generally resolved with a reduction in the patients' oral dopaminergic medication. The safety profile was similar across all dose cohorts.

The only immune responses seen were in cohort 3 where low-level antibody responses against the VSV-G envelope protein were detected in four of the six patients, and in three of these four patients, antibodies to $\mathrm{p} 26$ protein (part of the gag protein that makes up the viral particle) were observed. ${ }^{14}$

\section{Efficacy}

Similar to the previously reported data for the 6- and 12-month assessments, a significant reduction in mean UPDRS part III (off) motor scores 

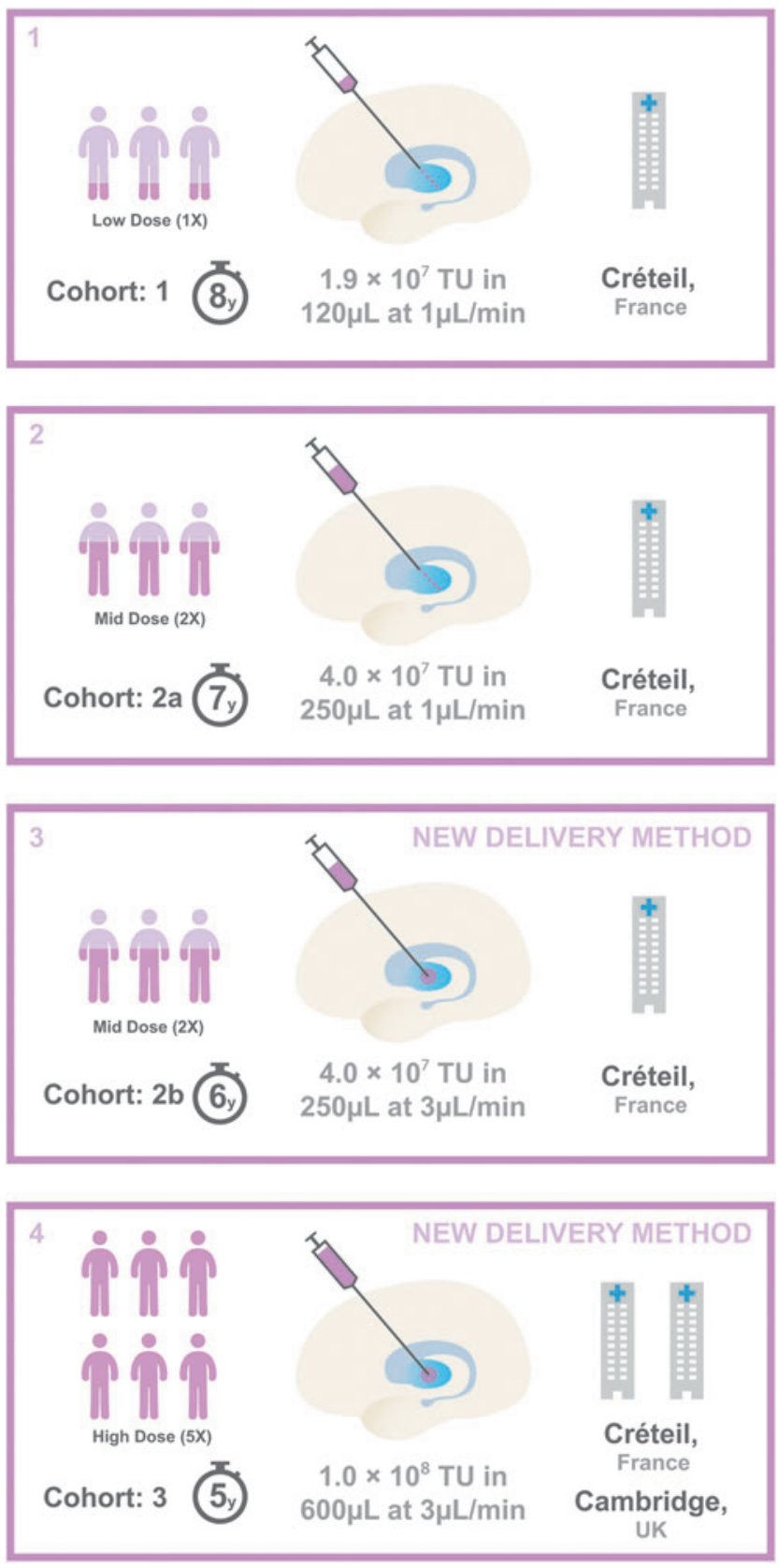

Figure 1. Trial profile. Box 1 represents cohort 1: $n=3$ patients included at dose level 1 (low dose, $1.9 \times 10^{7}$ transducing units [TU]; 8 years of followup), which involved four needle tracks of five ProSavin deposits per track in each motor putamen. Box 2 represents cohort 2: $n=3$ patients at dose level 2 (mid dose, $4.0 \times 10^{7} \mathrm{TU} ; 7$ years of follow-up), which involved five needle tracks of five ProSavin deposits in each track placed within the motor putamen. Box 3 represents cohort $2 \mathrm{~b}: n=3$ patients at dose level 2 (mid dose, $4.0 \times 10^{7} \mathrm{TU}$; 6 years of follow-up), with the new delivery method leading to three needle tracks with one deposit per track in each motor putamen. Box 4 represents cohort 3: $n=6$ patients at dose level 3 (high dose, $1 \times 10^{8} \mathrm{TU}$; 5 years of follow-up), with the new delivery method of three needle tracks, one deposit per track, in each motor putamen. A modified delivery method of administration was introduced for cohorts $2 b$ and 3 to increase the rate of delivery from 1 to $3 \mu \mathrm{L} / \mathrm{min}$ and a reduction of diameter of the cannula from 25 to 28 gauge. compared to baseline scores was observed across the 14 patients evaluated after 2 years of follow-up (Table $3 ; 29.2$ vs. $37.4, p<0.05$ ). Of the 14 patients, 10 showed sustained improvements from baseline at this time point. No statistically significant difference was seen between the differently dosed cohorts. Although four patients who received DBS were withdrawn from the efficacy analysis at follow-up after the 2- or 3-year assessments, 10/11 patients and 8/10 patients continued to demonstrate an improvement in UPDRS III (off) scores relative to baseline at the 3- or 4-year follow-up, respectively. The magnitude of improvement in these patients was generally similar to the effects observed at the 12- and 24-month time points. Of the patients who reached the 5- or 6-year followup, six out of nine patients and four out of six patients continued to have improved UPDRS III (off) scores relative to their baseline, which would also be consistent with the fact that they did not require further intervention with DBS.

No significant improvements in UPDRS part III (on) motor scores, compared to baseline, were observed for up to 2 years of follow-up (Table 3). All patients in the low-dose cohort, and three of the five mid-dose patients who could be evaluated, showed worsening UPDRS part III (on) scores compared to baseline at the 3-year follow-up. However, in the highdose cohort, all of the patients who were evaluated from 3 years onwards showed equivalent or improved scores relative to baseline at every time point.

The previously reported significant reduction in mean total UPDRS (off) scores compared to baseline scores at 1 year was maintained at the 2 -year follow-up time point in the 14 evaluable patients (Table $3 ; 69 \cdot 6$ vs. $58 \cdot 3, \mathrm{p}<0.05) .{ }^{14}$ No significant improvement in mean total UPDRS (on) scores at 2 years versus baseline was observed (24.4 vs. 27.3; $p=$ n.s.), and there were no sustained improvements observed in the majority of patients at longer follow-up times (Table 4).

Analysis of the UPDRS I, II (on and off), and IV scores demonstrated no significant differences from baseline scores in the 14 patients evaluated at 2 years (Supplementary Tables S4-S6). However, the majority of patients who could be evaluated showed improved or sustained scores from baseline up to the 4-year assessment. In the smaller numbers of patients who were followed up beyond 4 years, responses were generally similar or less favorable than baseline. Analysis of PDQ-39 scores demonstrated similar scores to baseline at the 2-year follow-up (Supplementary Table S7; 32.5 vs 32.1, $p=$ n.s.). At later time points, around half of patients assessed showed a gradual decline in scores. 
Table 2. All drug-related adverse events

\begin{tabular}{|c|c|c|c|c|c|}
\hline & \multicolumn{4}{|c|}{ Number of events } & \multirow{2}{*}{$\begin{array}{c}\text { Number of } \\
\text { patients }\end{array}$} \\
\hline & Mild & Moderate & Severe & Total & \\
\hline Total number of adverse events & 87 & 6 & 3 & 96 & 15 \\
\hline Nervous system disorders & 64 & 3 & 1 & 68 & 15 \\
\hline Dyskinesia & 30 & 2 & 1 & 33 & 11 \\
\hline On and off phenomenon & 22 & 0 & 0 & 22 & 11 \\
\hline Headache & 4 & 0 & 0 & 4 & 3 \\
\hline Akinesia & 3 & 0 & 0 & 3 & 3 \\
\hline Balance disorder & 1 & 0 & 0 & 1 & 1 \\
\hline Brain edema $^{a}$ & 1 & 0 & 0 & 1 & 1 \\
\hline Dysarthria & 1 & 0 & 0 & 1 & 1 \\
\hline Speech disorder & 1 & 0 & 0 & 1 & 1 \\
\hline Tremor & 0 & 1 & 0 & 1 & 1 \\
\hline Psychiatric disorders & 9 & 1 & 1 & 11 & 7 \\
\hline Delusional perception & 3 & 0 & 0 & 3 & 3 \\
\hline Anxiety & 1 & 1 & 0 & 2 & 2 \\
\hline Hallucination & 2 & 0 & 0 & 2 & 2 \\
\hline Abnormal dreams & 1 & 0 & 0 & 1 & 1 \\
\hline Acute psychosis & 0 & 0 & 1 & 1 & 1 \\
\hline Confused state & 1 & 0 & 0 & 1 & 1 \\
\hline Hallucination, visual & 1 & 0 & 0 & 1 & 1 \\
\hline Investigations & 7 & 0 & 0 & 7 & 5 \\
\hline $\begin{array}{l}\text { Nuclear magnetic resonance } \\
\text { imaging brain abnormal }\end{array}$ & 3 & 0 & 0 & 3 & 3 \\
\hline $\begin{array}{l}\text { Nuclear magnetic resonance } \\
\text { imaging abnormal }\end{array}$ & 2 & 0 & 0 & 2 & 2 \\
\hline Weight decreased & 1 & 0 & 0 & 1 & 1 \\
\hline Weight increased & 1 & 0 & 0 & 1 & 1 \\
\hline $\begin{array}{l}\text { Musculoskeletal and connective } \\
\text { tissue disorders }\end{array}$ & 4 & 0 & 0 & 4 & 4 \\
\hline Back pain & 1 & 0 & 0 & 1 & 1 \\
\hline Musculoskeletal pain & 1 & 0 & 0 & 1 & 1 \\
\hline Myalgia & 1 & 0 & 0 & 1 & 1 \\
\hline Neck pain & 1 & 0 & 0 & 1 & 1 \\
\hline $\begin{array}{l}\text { Injury, poisoning, and } \\
\text { procedural complications }\end{array}$ & 2 & 0 & 0 & 2 & 2 \\
\hline Fall & 1 & 0 & 0 & 1 & 1 \\
\hline Subdural hematoma ${ }^{\mathrm{b}}$ & 1 & 0 & 0 & 1 & 1 \\
\hline Blood and lymphatic system disorders & 0 & 1 & 0 & 1 & 1 \\
\hline Anemia & 0 & 1 & 0 & 1 & 1 \\
\hline Gastrointestinal disorders & 1 & 0 & 0 & 1 & 1 \\
\hline Nausea & 1 & 0 & 0 & 1 & 1 \\
\hline Renal and urinary disorders & 0 & 1 & 0 & 1 & 1 \\
\hline Glomerulonephritis & 0 & 1 & 0 & 1 & 1 \\
\hline
\end{tabular}

\footnotetext{
${ }^{a}$ Along the injection site only.

${ }^{\mathrm{b}}$ Bleeding under burr hole.
}

In long-term follow-up, the majority of patients continued to require a lower LEDD compared to baseline. In total, $10 / 14$ patients and 8/12 patients benefited from a reduction in LEDD compared to baseline at 2 and 3 years of follow-up, respectively (Table 5). Of the patients followed up for 4,5 , and 6 years, $5 / 11$ patients, $5 / 10$ patients, and $4 / 6$ patients received a lower LEDD than baseline, respectively.

\section{DISCUSSION}

The results of a Phase I/II clinical trial were previously reported describing the first-in-human use of a lentiviral-based gene therapy vector. In this study, ProSavin, an EIAV-derived lentiviral vector, was shown to have a favorable safety profile and encouraging efficacy signals following injection into the motor striatum of 15 patients with Parkinson's disease. ${ }^{14}$

The data reported here describes follow-up, for up to 8 years, of patients from the Phase I/II study and provides important additional information on the long-term safety and potential efficacy of this therapeutic approach. The safety data are generally consistent with those previously reported, ${ }^{14}$ with no drug- or procedure-related serious AEs during follow-up. The majority of drug-related AEs were on-medication dyskinesias adequately managed by lowering their L-Dopa medication, and encouragingly, the majority of drug-related AEs occurred within the first 12 months after treatment.

Eight patients received treatment with DBS, as they developed worsening off periods alternating with L-Dopa dyskinesias as a result of disease progression. It should be noted that no safety issue was observed with lead implantation or high frequency stimulation of the subthalamic nucleus in any of these cases (S. Palfi, pers. commun.). There was a very similar safety profile before and after DBS (compare Table 2 and Supplementary Table S1).

In terms of efficacy, the significant improvement in motor function previously reported up to 12 months was maintained at 2 years across the 14 patients that were assessed at this time point (with one patient withdrawing consent for off assessments after 12 months of follow-up). Although statistical analyses were not performed beyond this time point, as several patients were withdrawn from the efficacy part of the study by virtue of having had DBS, the majority of patients who remained in the open-label follow-up continued to show improvements in their UPDRS (III) off scores at all time points. These efficacy findings are consistent with the fact that the lentiviral vector genome is integrated into the host-cell genome and transgene expression is maintained long term, ${ }^{16}$ as has recently been shown following administration of an EIAV lentiviral vector into the retina. ${ }^{17}$ Nonetheless, Parkinson's disease is a progressive disease. So, it is encouraging that the data indicate that the levels of dopamine achieved through this gene therapy approach may be sufficient to sustain a positive motor behavioral effect for several years.

Considering only the patients who were evaluated at the longer-term follow-up time points, it is interesting to note that patients M6, M9, H12, and H13, who were diagnosed with Parkinson's disease 
Table 3. UPDRS part III scores in on and off states for each patient, by time point-post DBS data excluded

\begin{tabular}{|c|c|c|c|c|c|c|c|c|}
\hline Patients & Baseline & 6 months & 12 months & 24 months & 36 months & 48 months & 60 months & 72 months \\
\hline \multicolumn{9}{|c|}{ UPDRS part III off score (\% change from baseline) } \\
\hline L1 & 23 & $12(-48 \%)$ & $13(-43 \%)$ & $16(-30 \%)$ & $20(-13 \%)$ & $19(-17 \%)$ & $29(26 \%)$ & $28(22 \%)$ \\
\hline L2 & 30 & $26(-13 \%)$ & $27(-10 \%)$ & $30(0 \%)$ & $35(17 \%)$ & $32(7 \%)$ & $31(3 \%)$ & $26(-13 \%)$ \\
\hline L3 & 28 & $20(-29 \%)$ & $19(-32 \%)$ & $20(-29 \%)$ & $21(-25 \%)$ & $22(-21 \%)$ & $26(-7 \%)$ & $27(-4 \%)$ \\
\hline M4 & 29 & $21(-28 \%)$ & $24(-17 \%)$ & $30(3 \%)$ & $26(-10 \%)$ & $27(-7 \%)$ & $34(17 \%)$ & NA \\
\hline M5 & 30 & $24(-20 \%)$ & $26(-13 \%)$ & $19(-37 \%)$ & $24(-20 \%)$ & $24(-20 \%)$ & $29(-3 \%)$ & $29(-3 \%)$ \\
\hline M6 & 34 & $16(-53 \%)$ & $15(-56 \%)$ & $18(-47 \%)$ & $16(-53 \%)$ & $15(-56 \%)$ & $15(-56 \%)$ & $24(-29 \%)$ \\
\hline M7 & 49 & $34(-31 \%)$ & $39(-20 \%)$ & $44(-10 \%)$ & NA & NA & NA & NA \\
\hline M8 & 38 & $24(-37 \%)$ & $32(-16 \%)$ & $39(3 \%)$ & NA & NA & NA & NA \\
\hline M9 & 46 & $18(-61 \%)$ & $24(-48 \%)$ & $22(-52 \%)$ & $28(-39 \%)$ & $26(-43 \%)$ & $35(-24 \%)$ & $46(0 \%)$ \\
\hline $\mathrm{H} 10$ & 37 & $26(-30 \%)$ & $17(-54 \%)$ & $21(-43 \%)$ & $28(-24 \%)$ & NA & $19(-49 \%)$ & NA \\
\hline $\mathrm{H} 11$ & 35 & $24(-31 \%)$ & $27(-23 \%)$ & $39(11 \%)$ & NA & NA & NA & NA \\
\hline $\mathrm{H} 12$ & 52 & $46(-12 \%)$ & $39(-25 \%)$ & $46(-12 \%)$ & $41(-21 \%)$ & $28(-46 \%)$ & NA & NA \\
\hline $\mathrm{H} 13$ & 49 & $29(-41 \%)$ & $33(-33 \%)$ & $30(-39 \%)$ & $31(-37 \%)$ & $37(-24 \%)$ & $45(-8 \%)$ & NA \\
\hline $\mathrm{H} 14$ & 52 & $33(-37 \%)$ & $38(-27 \%)$ & NA & NA & NA & NA & NA \\
\hline H15 & 44 & $32(-27 \%)$ & $26(-41 \%)$ & $35(-20 \%)$ & $31(-30 \%)$ & $47(7 \%)$ & NA & NA \\
\hline \multicolumn{9}{|c|}{ UPDRS part III on score (\% change from baseline) } \\
\hline L1 & 6 & $7(17 \%)$ & $6(0 \%)$ & $7(17 \%)$ & $14(133 \%)$ & $10(67 \%)$ & $21(250 \%)$ & $24(300 \%)$ \\
\hline L2 & 8 & $10(25 \%)$ & $11(38 \%)$ & $11(38 \%)$ & $19(138 \%)$ & $19(138 \%)$ & $18(125 \%)$ & $21(163 \%)$ \\
\hline L3 & 11 & $7(-36 \%)$ & $7(-36 \%)$ & $10(-9 \%)$ & $15(36 \%)$ & $12(9 \%)$ & $19(73 \%)$ & $21(91 \%)$ \\
\hline M4 & 8 & $7(-13 \%)$ & $8(0 \%)$ & $10(25 \%)$ & $10(25 \%)$ & $9(13 \%)$ & $10(25 \%)$ & NA \\
\hline M5 & 14 & $14(0 \%)$ & $14(0 \%)$ & $13(-7 \%)$ & $16(14 \%)$ & $15(7 \%)$ & $17(21 \%)$ & $20(43 \%)$ \\
\hline M6 & 7 & $7(0 \%)$ & $6(-14 \%)$ & $9(29 \%)$ & $7(0 \%)$ & $6(-14 \%)$ & $6(-14 \%)$ & $5(-29 \%)$ \\
\hline M7 & 19 & $15(-21 \%)$ & $15(-21 \%)$ & $17(-11 \%)$ & NA & NA & NA & NA \\
\hline M8 & 15 & $13(-13 \%)$ & $15(0 \%)$ & $12(-20 \%)$ & NA & NA & NA & NA \\
\hline M9 & 9 & $5(-44 \%)$ & $5(-44 \%)$ & $8(-11 \%)$ & $12(33 \%)$ & $11(22 \%)$ & $14(56 \%)$ & $10(11 \%)$ \\
\hline $\mathrm{H} 10$ & 8 & $8(0 \%)$ & $8(0 \%)$ & $9(13 \%)$ & $8(0 \%)$ & NA & $8(0 \%)$ & NA \\
\hline $\mathrm{H} 11$ & 10 & $8(-20 \%)$ & $9(-10 \%)$ & $11(10 \%)$ & NA & NA & NA & NA \\
\hline $\mathrm{H} 12$ & 13 & $11(-15 \%)$ & $9(-31 \%)$ & $15(15 \%)$ & $12(-8 \%)$ & $12(-8 \%)$ & NA & NA \\
\hline $\mathrm{H} 13$ & 23 & $16(-30 \%)$ & $21(-9 \%)$ & $25(9 \%)$ & $14(-39 \%)$ & $20(-13 \%)$ & $19(-17 \%)$ & NA \\
\hline $\mathrm{H} 14$ & 23 & $24(4 \%)$ & $33(43 \%)$ & NA & NA & NA & NA & NA \\
\hline $\mathrm{H} 15$ & 18 & $20(11 \%)$ & $15(-17 \%)$ & $13(-28 \%)$ & $10(-44 \%)$ & $10(-44 \%)$ & NA & NA \\
\hline
\end{tabular}

between 9 and 26 years prior to ProSavin treatment, ${ }^{14}$ showed particularly encouraging improvements from baseline in their UPDRS III (off) scores, with changes of 12-24 points at the 4-year assessment. Patient M6 was also evaluated at 6 years, and continued to show an approximately $30 \%$ improvement in both UPDRS III on and off scores, with a sustained reduction in LEDD, and a 17-unit improvement in PDQ-39 scores from baseline.

Although these data provide strong evidence to support an efficacy benefit for ProSavin in Parkinson's disease patients, the overall magnitude of effects are within the range reported for placebo study arms, albeit over shorter time frames, in other clinical trials for PD using surgical interventions. ${ }^{8,13}$ The duration of such placebo effects have not been well studied. However, given that the improvements in motor scores were sustained for 6 years in some patients and confined to their "off" state assessments, combined with the fact that Parkinson's disease is a progressive neurodegenerative disease with an expected three- to four-point increase in the UPDRS part III (off) motor score per year, ${ }^{18,19}$ the likelihood that the findings reported are attributable to the study treatment is strong. Nonetheless, interpretation of these findings must still be viewed with caution until a larger comparator study has been undertaken with placebo treatments, especially given the extent of patient attrition over the follow-up period in this study. An attrition that is not unexpected, given that the study recruited patients at relatively advanced stages of disease.

Given the small sample populations, it is difficult to assess dose response. It was previously reported that there were indications of positive responses in patients receiving the highest dose of ProSavin. These patients had the most consistent LEDD reduction post intervention, the highest mean improvement in UPDRS III (off) motor scores at 1 year, and a significant change from baseline in ${ }^{11} \mathrm{C}$-raclopride binding potential. ${ }^{14} \mathrm{At}$ 2 years of follow-up, a similar mean improvement from baseline in UPDRS III (off) scores was observed in the mid- and high-dose groups, which was higher than in the low-dose group. Again, interpretation of these observations must be made 
Table 4. Total UPDRS scores in on and off states for each patient, by time point-post DBS data excluded

\begin{tabular}{|c|c|c|c|c|c|c|c|c|}
\hline Patients & Baseline & 6 months & 12 months & 24 months & 36 months & 48 months & 60 months & 72 months \\
\hline \multicolumn{9}{|c|}{ Total UPDRS off score } \\
\hline L1 & 49 & 30 & 30 & 37 & 44 & 43 & 67 & 62 \\
\hline L2 & 61 & 45 & 59 & 62 & 73 & 65 & 70 & 61 \\
\hline M4 & 63 & 50 & 52 & 69 & 59 & 59 & 65 & NA \\
\hline M5 & 58 & 54 & 53 & 30 & 47 & 40 & 60 & 54 \\
\hline M6 & 74 & 54 & 44 & 58 & 53 & 49 & 53 & 60 \\
\hline M9 & 68 & 44 & 54 & 51 & 56 & 58 & 71 & 89 \\
\hline $\mathrm{H} 10$ & 59 & 54 & 49 & 51 & 66 & NA & 57 & NA \\
\hline $\mathrm{H} 11$ & 71 & 58 & 65 & 79 & NA & NA & NA & NA \\
\hline $\mathrm{H} 12$ & 91 & 84 & 73 & 86 & 82 & 71 & NA & NA \\
\hline $\mathrm{H} 13$ & 90 & 47 & 53 & 49 & 57 & 50 & 74 & NA \\
\hline $\mathrm{H} 14$ & 94 & 63 & 64 & NA & NA & NA & NA & NA \\
\hline L3 & 35 & 15 & 18 & 17 & 22 & 27 & 39 & 49 \\
\hline M4 & 20 & 17 & 17 & 28 & 21 & 19 & 19 & NA \\
\hline M5 & 24 & 24 & 22 & 19 & 28 & 20 & 31 & 35 \\
\hline M6 & 23 & 25 & 22 & 26 & 25 & 17 & 31 & 22 \\
\hline M7 & 31 & 29 & 26 & 39 & NA & NA & NA & NA \\
\hline M8 & 31 & 27 & 29 & 22 & NA & NA & NA & NA \\
\hline M9 & 20 & 18 & 16 & 20 & 24 & 30 & 33 & 32 \\
\hline $\mathrm{H} 10$ & 21 & 18 & 21 & 20 & 22 & NA & 23 & NA \\
\hline $\mathrm{H} 11$ & 27 & 22 & 25 & 26 & $\mathrm{NA}$ & NA & $\mathrm{NA}$ & NA \\
\hline $\mathrm{H} 12$ & 25 & 24 & 21 & 29 & 34 & 33 & NA & NA \\
\hline $\mathrm{H} 13$ & 52 & 27 & 34 & 35 & 25 & 30 & 36 & NA \\
\hline $\mathrm{H} 14$ & 47 & 33 & 41 & NA & NA & NA & NA & NA \\
\hline
\end{tabular}

with caution due to the small patient numbers and the changes seen in the UPDRS III scores.

In conclusion, the new data demonstrate the long-term safety and promising efficacy profile of ProSavin in Parkinson's disease patients for up to 8

Table 5. L-Dopa equivalent dose (LEDD)— post DBS data excluded

\begin{tabular}{lcccccccc}
\hline & \multicolumn{1}{c}{6} & 12 & 24 & 36 & 48 & 60 & 72 \\
Patients & Baseline & months & months & $\begin{array}{c}\text { months } \\
\text { months }\end{array}$ & $\begin{array}{c}\text { months } \\
\text { months }\end{array}$ & months \\
\hline L1 & 2,547 & 2,257 & 2,382 & 2,507 & 2,507 & 3,102 & 986 & 1,461 \\
L2 & 1,329 & 1,319 & 1,103 & 1,019 & 1,582 & 1,582 & 1,530 & 1,680 \\
L3 & 1,998 & 1,448 & 750 & 1,149 & 1,282 & 999 & 875 & 1,575 \\
M4 & 2,164 & 2,164 & 1,025 & 1,229 & 1,487 & 2,015 & 2,414 & NA \\
M5 & 1,572 & 1,572 & 1,572 & 1,238 & 1,238 & 1,052 & 998 & 1,098 \\
M6 & 2,523 & 2,257 & 2,257 & 1,548 & 1,615 & 1,615 & 1,848 & 1,958 \\
M7 & 1,785 & 1,936 & 2,036 & 2,305 & NA & NA & NA & NA \\
M8 & 1,088 & 1,088 & 1,088 & 1,160 & NA & NA & NA & NA \\
M9 & 1,775 & 1,525 & 1,400 & 1,400 & 1,725 & 1,850 & 1,800 & 2,582 \\
H10 & 1,535 & 1,160 & 1,360 & 1,660 & 1,810 & 2,314 & 3,002 & NA \\
H11 & 1,844 & 1,549 & 1,615 & 2,148 & NA & NA & NA & NA \\
H12 & 1,180 & 1,030 & 1,130 & 1,055 & 1,165 & 2,253 & NA & NA \\
H13 & 1,691 & 1,391 & 1,391 & 1,391 & 1,391 & 1,125 & 1,125 & NA \\
H14 & 699 & 633 & 699 & NA & 699 & NA & NA & NA \\
H15 & 1,593 & 1,530 & 1,530 & 1,573 & 1,928 & 2,229 & 2,344 & NA \\
\hline
\end{tabular}

years of follow-up. These are the longest follow-up assessments reported in any Parkinson's disease gene therapy study. Although the results are encouraging, the data suggest that the optimal level of dopamine replacement may not have been achieved, since patients continued to require oral L-Dopa therapy to obtain maximal benefit, and some of the more severely affected patients required DBS 2-6 years following ProSavin administration. Further dose escalation using ProSavin would be challenging due to limitations on vector titers using current production processes and the volume of vector that can be safely administered into the human striatum. Therefore, a new vector (OXB-102) has been recently developed in which the configuration of three dopamine biosynthesis enzymes was further optimized to increase the capacity for dopamine production significantly compared to ProSavin. ${ }^{20}$ This vector is under preclinical development and, pending regulatory approval, will be assessed in a new Phase I/II study to determine the appropriate dose before a larger placebo-controlled Phase IIb clinical trial is undertaken. 


\section{ACKNOWLEDGMENTS}

We would like to thank the current and former staff at Henri Mondor Hospital, CEA, Oxford BioMedica and John van Geest Centre for Brain Repair, and Addenbrooke's Hospital. In addition, we would like to thank the members of the datamonitoring committee and of course the 15 patients for their commitment to participate in this study.

Oxford BioMedica (UK) Ltd. funded the study and was the study sponsor, with responsibility for the trial design, manufacture, and supply of the drug, data collection, clinical monitoring, and pharmacovigilance. Additional funding was provided by ARSC Foundation, and the NIHR funded Biomedical Research Centre award to Addenbrooke's Hospital and the University of Cambridge. R.A.B. is an NIHR Senior Investigator.

\section{AUTHOR DISCLOSURE}

G.S.R., K.A.M., and N.J.T. are employees, or former employees, of Oxford BioMedica, which funded this study. They and their families have ownership interests in the company. S.P., R.A.B., P.B., and K.H. are consultants, or former consultants, of Oxford BioMedica. No competing financial interests exist for the remaining authors.

\section{REFERENCES}

1. Schapira AH. Etiology and pathogenesis of Parkinson disease. Neurol Clin 2009;27:583-603.

2. de Lau LM, Breteler MM. Epidemiology of Parkinson's disease. Lancet Neurol 2006;5:525-535.

3. Prashanth LK, Fox S, Meissner WG. L-dopainduced dyskinesia-clinical presentation, genetics, and treatment. Int Rev Neurobiol 2011;98:31-54.

4. Ahlskog JE, Muenter MD. Frequency of levodopa-related dyskinesias and motor fluctuations as estimated from the cumulative literature. Mov Disord 2001;16:448-458.

5. Wu K, Politis M, Piccini P. Parkinson disease and impulse control disorders: a review of clinical features, pathophysiology and management. Postgrad Med J 2009;85:590-596

6. Olanow CW, Obeso JA, Stocchi F. Continuous dopamine-receptor treatment of Parkinson's disease: scientific rationale and clinical implications. Lancet Neurol 2006;5:677-687.

7. Muramatsu S, Fujimoto K, Kato S, et al. A Phase I study of aromatic L-amino acid decarboxylase gene therapy for Parkinson's disease. Mol Ther 2010;18:1731-1735.

8. Christine CW, Starr PA, Larson PS, et al. Safety and tolerability of putaminal AADC gene therapy for Parkinson disease. Neurology 2009;73: 1662-1669.

9. Eberling JL, Jagust WJ, Christine CW, et al. Results from a Phase I safety trial of hAADC gene therapy for Parkinson disease. Neurology 2008;70: 1980-1983

10. Marks WJ Jr, Ostrem JL, Verhagen L, et al. Safety and tolerability of intraputaminal delivery of CERE-120 (adeno-associated virus serotype 2neurturin) to patients with idiopathic Parkinson's disease: an open-label, Phase | trial. Lancet Neurol 2008;7:400-408.

11. Kaplitt MG, Feigin A, Tang C, et al. Safety and tolerability of gene therapy with an adenoassociated virus (AAV) borne GAD gene for Parkinson's disease: an open label, Phase I trial. Lancet 2007;369:2097-2105

12. LeWitt PA, Rezai AR, Leehy MA, et al. AAV2-GAD gene therapy for advanced Parkinson's disease: a double-blind, sham-surgery controlled, randomised trial. Lancet Neurol 2011;10:309-319.

13. Marks WJ Jr, Bartus RT, Siff ert J, et al. Gene delivery of AAV2-neurturin for Parkinson's disease: a double-blind, randomised, controlled trial. Lancet Neurol 2010:9:1164-1172.

14. Palfi S, Gurruchaga JM, Ralph GS, et al. Longterm safety and tolerability of ProSavin, a lentiviral vector-based gene therapy for Parkinson's disease: a dose escalation, open-label, Phase 1/2 trial. Lancet 2014; 383: 1138-1146.

15. Azzouz M, Martin-Rendon E, Barber RD, et al. Multicistronic lentiviral vector-mediated striatal gene transfer of aromatic L-amino acid decarboxylase, tyrosine hydroxylase, and GTP cyclo- hydrolase I induces sustained transgene expression, dopamine production, and functional improvement in a rat model of Parkinson's disease. J Neurosci 2002;22:10302-10312.

16. Jarraya B, Boulet $S$, Ralph GS, et al. Dopamine gene therapy for Parkinson's disease in a nonhuman primate without associated dyskinesia. Sci Transl Med 2009;1:2ra4.

17. Campochiaro PA, Lauer AK, Sohn EH, et al. Lentiviral vector Gene transfer of Endostatin/angiostatin for Macular degeneration (GEM) study. Hum Gene Ther 2017:28:99-111.

18. Eggers C, Pedrosa DJ, Kahraman D, et al. Parkinson subtypes progress differently in clinical course and imaging pattern. PLoS One 2012;7: e46813.

19. Olanow CW, Goetz CG, Kordower JH, et al. A double-blind controlled trial of bilateral fetal nigral transplantation in Parkinson's disease. Ann Neurol 2003;54:403-414.

20. Stewart HJ, Ralph GS, Fong-Wong L, et al. Optimizing transgene configuration and protein fusions to maximize dopamine production for the gene therapy of Parkinson's disease. Hum Gene Ther Clin Dev 2016;27:100-110.

Received for publication April 14, 2018; accepted after revision August 14, 2018

Published online: August 28, 2018 